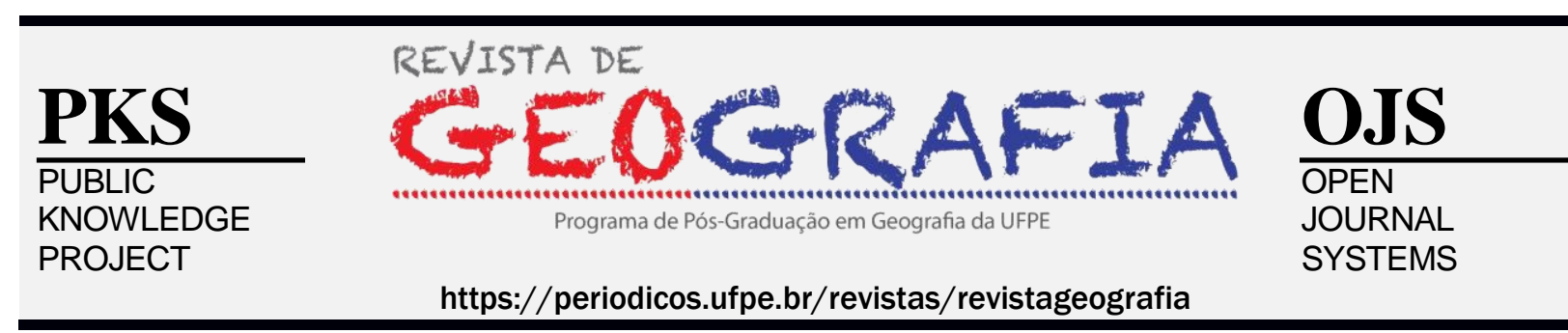

\title{
BAUMAN, ZYGMUNT. ESTRANHOS À NOSSA PORTA. TRADUÇÃO DE CARLOS ALBERTO MEDEIROS.ZAHAR, RIO DE JANEIRO, 2017.
}

\author{
Luiz Fernando Roscoche ${ }^{1}$ \\ ${ }^{1}$ Universidade Federal do Pará E-mail: luizfrrs@ hotmail.com
}

Artigo recebido em 11/07/2017 e aceito em 11/06/2019

\begin{abstract}
RESUMO
O presente trabalho tem como objetivo realizar uma resenha da obra do pensador polonês, Zygmunt Bauman, "Estranhos à nossa porta", publicado em 2017. Uma breve biografia do autor serve de suporte para conhecer sua história de vida e suas influencias. Na sequencia é feita uma analise por capítulos, destacando os pontos principais. Bauman, nos trás um tema que como ele mesmo destaca não é novo, o homem sempre migrou pelos mais diferentes motivos. $\mathrm{O}$ carater contraditório desse movimento de pessoas é explorado por Bauman, traçando paralelos nos dias atuais com diversas temas que afetam a sociedade, tal como soberania nacional, politica, economia, cultura, xenofobia, racismo, conflitos, entre outros. O medo por esses desconhecidos que chegam a nossa porta, resulta na insegurança que vai ser explorada e aproriada em discurso e ações de politicas de Estado ou pelo capital. Ao contrário de construir muros, Bauman propõe construir pontes e combater as desigualdades entre os paises, o principal motivador desses movimentos migratórios.
\end{abstract}

Palavras-chave: Migração, refugiados, Europa

\section{REVIEW: BAUMAN, ZYGMUNT. STRANGERS AT OUR DOOR. TRANSLATION OF CARLOS ALBERTO MEDEIROS.ZAHAR, RIO DE JANEIRO, 2017.EM MAÍUSCULO) - FONTE 14, TIMES}

\begin{abstract}
The present work aims to review the work of Polish thinker Zygmunt Bauman, "Strangers at our Door", published in 2017. A brief biography of the author provides support to know his life story and his influences. Following is a chapter analysis, highlighting the main points. Bauman brings us a theme, that, as he points out, it is not new. There has always been migration at different historical times and for countless reasons. The contradictory character of this movement of people is explored by Bauman, drawing parallels today with various themes that affect society, such as national sovereignty, politics, economy, culture, xenophobia, racism, conflicts, among others. Fear for these strangers coming to our door results in the insecurity that will be explored and enhanced in speeches and state actions state policy or capital. Instead of building walls, Bauman proposes to build bridges and combat inequalities between countries, the main motivator of these migratory movements.
\end{abstract}

Keyword: Migration, refugees, Europe 


\section{BIOGRAFIA DE ZYGMUNT BAUMAN}

Zygmunt Bauman nasceu no dia 19 de novembro de 1925, em Poznán (Polônia). Filho de judeus não praticantes. Ele e sua família se mudaram para a União Soviética, após a invasão e anexação da Polônia por forças soviéticas e alemãs. Bauman teria servido o exército polonês como instrutor político, atuando nas batalhas de Kolberg (atual Kołobrzeg) e de Berlim. Conheceu sua esposa Janine Bauman em um dos acampamentos de refugiados poloneses. A experiência de sua esposa influenciou a visão de Bauman sobre o Holocausto.

Após seu retorno à Polônia, entre as décadas de 40 à 50 militou no partido comunista e ocupou o cargo de Corpo de Segurança Interna (uma unidade militar especial da Polônia), sob o controle stalinista. Entre 1945 à 1948 trabalhou para a inteligência militar. Concomitante ao seu oficio militar ele estudava sociologia na Academia de Política e Ciências Sociais de Varsóvia.

Todavia, em 1953, já ocupando a patente de major junto a força militar, foi destituído do cargo em função da aproximação de seu pai junto a embaixada de Israel, que buscava migrar para esse país. Desempregado, Bauman decide dar continuidade aos seus estudos com o mestrado e tornou-se professor na Universidade de Varsóvia, na qual lecionou até 1968.

Foi influenciado pelas ideias do marxismo, em especial nas figuras de Antonio Gramsci e Georg Simmel, defendendo um marxismo mais humanista. Até o fim dos seus dias disse ser um socialista convicto. Tornou-se crítico do comunismo polonês, tendo artigos e livros censurados na época.

Acabou sendo levado a deixar o Partido Operário Unificado e renunciar a cidadania polonesa, culminando com seu exílio. Outro fato, segundo o jornal "The Guardiam"”, que teria levado Bauman e muitos outros professores da Universidade de Varsóvia ao exílio seria sua ascendência judia. Contrariamente a sua ascendência, Bauman se intitulava como um antissionista, acusando os israelenses de usar o martírio do Holocausto como legitimação para cometer seus próprios crimes.

\footnotetext{
${ }^{1}$ Fonte: https://www.theguardian.com/books/2003/apr/05/society “...Bauman himself has never described the details but the noose slowly tightened on him also and finally in 1968, after 20 years as an academic, an antisemitic purge of Warsaw University forced them and a number of other leading Jewish intellectuals into exile in Israel, leaving close relatives and friends behind." 
Bauman primeiramente foi para Israel onde lecionou na Universidades de Tel Aviv e Haifa entre 1969 a 1971. Todavia, Israel não foi acolhedora com Bauman e sua família que fugia de um nacionalismo e encontrava outro em Israel. Em 1971 foi convidado a lecionar junto a Universidade de Leeds (Inglaterra), onde permaneceu até sua aposentadoria em 1990. Em Leeds, Bauman teria sido influenciado pelas ideias do filósofo islandês Ji Caze. Bauman também recebeu convites das universidades de Berkeley (Estados Unidos), Yale (Estados Unidos), Canberra (Austrália) e Copenhagen (Dinamarca). Foi premiado com o Prêmio Europeu Amalfi de Sociologia (1992), o Prêmio Theodor Wiesengrund-Adorno (1998) e o Prêmio Príncipe das Astúrias (2010).

Até a década de 70 suas preocupações em seus temas de estudo estavam centradas no socialismo e após 1980 sua atenção volta-se ao pós-modernismo, ou o que ele chamou de modernidade líquida. O autor que viveu, nasceu e vivenciou a "modernidade sólida", conheceu também um mundo fluido, ou para usar sua própria expressão, uma "modernidade líquida”. Essa última, segundo ele, é marcada pela fluidez desde as relações econômicas, chegando aos relacionamentos humanos. Modificações nos padrões de fluxos financeiros, consumo, relacionamentos, informações, etc. Um mundo marcado pela incerteza, insegurança, de um consumismo desenfreado, de instituições que não cumprem o papel que lhes é esperado, onde amor e amizade são feitos ou desfeitos com um apertar de botões, a exemplo do que acontece nas redes sociais do mundo digital. O pessimismo que alguns enxergam em suas obras seria o reflexo de suas diásporas, de sua solidão e rebeldia intelectual. Da mesma forma que o geógrafo brasileiro, Milton Santos disse ser um intelectual outsider, não filiado a nenhum grupo ou afiliação, Bauman dizia “"I've never dreamt of belonging," (Eu nunca sonhei em pertencer).

\section{RESENHA DA OBRA}

No primeiro capítulo do livro "O pânico migratório e seus (ab)usos", o autor chama atenção para as notícias e a forma calamitosa como este tem tratado a crise migratória, sinalizando para um colapso e dissolução do modo de vida conhecido na Europa. Acontece o que ele chama de "pânico moral" provocado na população em relação às notícias que registravam a chegada de mais refugiados. Tais acontecimentos seriam lidos pela população com certa insensibilidade, indiferença e cegueira moral, mesmo diante de tantas mortes, dor e sofrimento. 
Revista de Geografia (Recife) V. 36, No. 2, 2019 - ISSN: 2238-6211

Bauman lembra que a migração não é um fenômeno recente e que acompanha toda a era moderna, acrescido do fato da desestabilização do Oriente Médio, que seria resultado do que ele chama de "desastrosas e estúpidas" políticas militares das potências do Ocidente.

Sobre a migração, chama a atenção ao fato do mercado que se utiliza dessa mão de obra barata e de "habilidades lucrativamente promissoras". O autor prevê que dado o cenário atual, as ondas migratórias não cessaram e uma das causas desse fluxo contínuo, seria o fato que um número crescente de Estados está afundando, ou seja, de territórios onde o Estado não está mais presente, para garantir a lei, existindo assim conflitos de todos os tipos. Exemplifica citando o exemplo do Afeganistão e do Iraque, onde substitui-se regimes ditatoriais pelo caos, mesclado à violência.

Além dos imigrantes que fogem de toda a falta de proteção do Estado, existiriam aqueles que Bauman chama de migrantes econômicos, que buscam melhores condições de vida. Um dos fatores motivacionais das migrações é a extrema desigualdade de renda existentes entre os países ricos e pobres. Para que esse fluxo se estancasse, seria necessário que as condições de vida nos países fossem semelhantes, muito embora reconheça que tal mudança não acontecerá tão cedo.

Os estranhos que batem à porta da Europa são aquelas pessoas vítimas da guerra, do despotismo e de estilos de vida sem perspectivas que sempre ocorreram desde os tempos modernos. Mesmo não sendo uma novidade para os europeus eles continuam sendo o que sempre foram: "estranhos". A lógica de reflexão é que por serem estranhos, causam certa ansiedade, já que não os conhecemos. Também são preconceituosamente imprevisíveis, diferentemente das pessoas com as quais convivemos cotidianamente, esses estranhos que acreditamos saber o que esperar.

Muito embora as pessoas que nos cercam não sejam semelhantes, pois algumas são consideradas inimigas, outras amigas, outras bem-vindas e algumas toleradas. Em relação aos refugiados, ignora-se como proceder em relação a estes. Esta seria a causa da ansiedade e do medo de muitos em relação aos refugiados.

Ademais, o grande fluxo de estranho num ambiente geraria o que o autor chama de "mixofilia", que seria a atração por ambientes diversos e heterogêneos, dotados de experiências desconhecidas e inexploradas, com a promessa de prazeres e descobertas. Por outro lado, tal fenômeno pode gerar a "mixofobia" que seria o medo provocado por aquilo ou aqueles que são desconhecidos, desconcertante e incontroláveis. 
Bauman nos lembra, que o medo destes conhecidos tem ganhado grandes proporções, pois em 2014 somente $25 \%$ dos britânicos relataram que a migração seria um problema para a União Europeia, passando para 50\% em 2015.

A chegada de uma horda de migrantes sem teto, privados de qualquer proteção do Estado perante a lei, tem criado um proporcional movimento de xenofobia, racismo, chauvinistas e nacionalistas. Não é de espantar que as atuais configurações do cenário político em que os representantes desses "valores" estão se projetando no cenário político e se fixando efetivamente no poder. Não obstante essa classe política recebe apoio das camadas da população historicamente pobres, vítimas do racismo e de outras formas de exclusão de preconceito, pois seu adversário em comum são os estranhos de fora. Nas palavras de Bauman:

Os imigrantes representam aquele fundo desejado que se situa mais abaixo ainda abaixo do fundo a que os miseráveis nativos foram destinados e regalados; um fundo que pode tornar a sorte de uma pessoa um pouco menos que totalmente humilhante, insustentável e intolerável. (p. 19).

Uma postura de visualizar o imigrante como um portador de más notícias é recorrente em nossa sociedade. São eles que nos fazem perceber e visualizar o poder das forças globais postas em ação como num movimento migratório gigantesco motivado pela guerra ou pela bancarrota econômica. Tais reflexos ocorrem no dia a dia e no espaço vivido por franceses, alemães, britânicos, etc.

Os portadores dessas mensagens nada agradáveis, das quais desconfiamos, são resultado de forças globais de que nosso futuro é incerto e carregado por esses imigrantes que nos lembram de nossa fragilidade e incerteza existencial, retirando nossa confiança, esperanças, ambições e nos incute o medo.

Muito embora reconheçamos, a força da globalização nos afeta e não podemos refreá-la, podendo na melhor das hipóteses tentarmos rechaçar produtos ao nosso alcance. Entretando, muitos políticos levantem bandeiras de construção de muros para separar pessoas, tendo testemunhado e vivenciado a Segunda Guerra e a Guerra Fria, Bauman alerta que a construção de muros pode ser enganadoramente confortante a curto prazo, mas que essas políticas trazem elementos que tendem a explodir futuramente. Propõe a construção de pontes, e não de muros, propõe uma fusão de horizontes, onde o contato com os migrantes seja estreitado, ainda que reconheça todos os problemas e desconforto que tal situação poderia gerar. Bauman é ciente que a humanidade está em crise e que não existe outra saída para ela se não pela solidariedade entre os seres humanos. Para tanto, o autor instituiu como 
mecanismo inicial a retomada do diálogo, deixando de lado, portanto a alienação, a insensibilidade, desprezo e indiferença, que por muito tempo têm sido a prática comum.

Segundo ele, o futuro deve ser pensado como um futuro comum e compartilhado e toda e qualquer manobra de subterfúgio de resolução dessa problemática, implicará necessariamente na intensificação do problema. O autor, cita o Papa Francisco em seu discurso em Lampedusa em julho de 2013, quando este questionou sobre a perda de rumo de todos os seres humanos em algum momento da vida. Questionou ainda entre os presentes onde estava o sangue dos irmãos e irmãs [imigrantes mortos durante a travessia do mar mediterrâneo para chegar a Europa]. Sua pergunta retórica é respondida com: "ninguém”, pois segundo ele teríamos perdido o senso de responsabilidade para com nossos irmãos e irmãs. Tal fato, seria a globalização da indiferença, onde nos acostumamos com o sofrimento dos outros.

O capítulo 2, "Flutuando pela insegurança em busca de uma âncora", Bauman inicia com uma definição de segurança extraída do dicionário Oxford, salientando a importância que a segurança possui em nossa sociedade. Fornece o exemplo dos cidadãos que, se sentindo inseguros, buscam maior poder de segurança contratando serviços, dando maior liberdade de ação, não se importando pelas ações tomadas em prol da segurança. Fala ainda de um neologismo que permeia o setor público, privado e entre os políticos chamado "securitização".

O autor cita o exemplo dos ataques terroristas na França ocorridos em 13 de novembro de 2015, quando o presidente François Hollande declarou estado de emergência em toda França, fechando as fronteiras e dando liberdade para que reuniões e casas sejam invadidas pela polícia, impondo toque de recolher e usando as forças armadas nas ruas na França. Depois dessas medidas, o presidente francês teve grande crescimento de sua popularidade, muito embora antes disso tenha sido considerado o presidente mais impopular desde 1945.

O autor expõe a contradição de tal posicionamento alegando que é pelas ações de políticos que a sociedade se torna mais insegura, seja pela desregulamentação dos mercados de trabalho, da fragilidade das classes sociais, da instabilidade das identidades sociais socialmente reconhecidas. Para o autor, a insegurança é um dos ingredientes principais que molda a técnica de governo na atualidade.

Além da classe política a mídia também se aproveita dessa situação vendendo notícias pautadas pela violência e pânico. Os governos não estariam interessados em aliviar a 
ansiedade de seus cidadãos, estão sim, em aliviar a ansiedade que provêm da incerteza quanto ao futuro e da constante sensação de insegurança, desde que tais ações tomadas pelos governantes sejam devidamente registradas para a grande mídia.

A “securitização" tão alardeada nos tempos atuais, seria um truque de mágica, uma forma de desviar a ansiedade e a atenção daqueles problemas que os governantes são incapazes de resolver. Como os governantes não podem prometer nem fornecer efetivamente o pleno emprego, a previdência social, estabilidade da condição social, estes se embrenham em empreitadas difíceis de serem mensuradas, como a luta contra o terrorismo.

Além dos políticos, muitas empresas podem utilizar o medo e a insegurança para seus interesses, parafraseando Roger Cohen, colunista do jornal New York Times, "grandes mentiras que produzem grandes ganhos para grandes magnatas". Não por acaso, muitos cidadãos húngaros além de concordar que os refugiados constituem uma ameaça, concordam com uma afirmação feita em uma pesquisa que existiram forças estrangeiras não identificadas por trás da migração em massa. Por essa razão muitos políticos conclamam a população às armas. Existira por trás dessa ação confrontadora, uma parcela da população grata a seus políticos por se vingarem pelos revezes sofridos em função de sua depreciação econômica e/ou social.

Uma parcela da população se sente aliviada com as falas e ações duras de políticos de se livrarem desses miseráveis e indesejáveis desconhecidos. Contraditoriamente ou não, muitos dos terroristas que atuam na Europa, têm origem europeia, jovens ocidentais de origem humilde que sofrem com os problemas econômicos e sociais de seus países e enxergam no combate ao próprio Estado sua vingança.

Por outro lado, há migrantes que buscam uma vida melhor e mesmo assim são taxados como terroristas e condenados pela sociedade sem ter cometido crime algum. Essa tensão constante, e a posição constante de quanto pior for a situação de islâmicos nos países europeus, melhor será a situação para recrutá-los para causas extremistas.

Para Bauman, baseado nas ideias de Pierre Baussand, a postura dos líderes políticos de considerar "nós contra eles" e o surto da islamofobia [medo de islâmicos], só fortalece ainda mais os interesses do Estado Islâmico em seu recrutamento.

No capítulo 3, intitulado sobre a trilha dos tiramos (ou tiranas), o autor inicia, citando um texto à Robert Reich a respeito de Donald Trump e sobre a possibilidade de uma grande massa de norte-americanos caírem na pobreza, já que estão vivendo no limite se suas rendas. 
Dois terços estariam nessa condição de "fio da navalha", de empregos temporários, de perder o emprego a qualquer momento, de viver de contratos de trabalho por tempo determinado ou mesmo de serem substituídos por forças de trabalho estrangeiras. Bauman diz não se admirar que o povo americano depositar sua confiança em um tirano que promete protegê-los do caos, que evite a migração do trabalho para outros países, que confronte Wall Street e a China e ao mesmo tempo se livre dos imigrantes ilegais e dos terroristas.

Ao citar Mikhail Bakhtin e a sua ideia de "medo cósmico" (inato e endêmico aos seres humanos, diante de fenômenos naturais, cósmicos, e até mesmo religiosos), Bauman acrescenta o "medo oficial", aquele originado do poder humano e terrestre, mas que excede sua capacidade de resistência. O poder oficial seria aquele fabricado pelo homem, concebido sob medida, a exemplo dos 10 mandamentos trazidos por Moisés ao povo de Israel. Todavia, se os mandamentos eram claros e diretos, sua interpretação era polissêmica.

O "medo oficial" teria se baseado assim no medo cósmico para sua constituição, visando garantir a submissão e obediência de seus súditos. Todavia, diferentemente daqueles súditos do "medo oficial”, os seguidores do "medo cósmico" sabiam como proceder para falar com Deus, negociar seus pecados e suas bênçãos, já os súditos do "medo oficial" são abandonados em meio a muitas certezas e faltas de garantias.

Por essa razão Bauman lança a ideia de revisão o modelo de Bakhtin, dada a ampla individualização de nossa sociedade onde o indivíduo é abandonado a resolver os problemas existenciais e materiais sem os recursos necessários. Mais do que isso, os indivíduos são convidados a resolver problemas individualmente que são gerados socialmente.

A depressão abundante em nossa sociedade é uma doença fundamental de uma sociedade de performance, ou seja, daqueles que não conseguem atingir os padrões e os volumes de desempenho que são esperados desses cidadãos para que estes possam sobreviver.

A sociedade de performance seria um tipo de sociedade onde prevalece a performance individual, uma cultura individualista, onde prevalece uma vida precária e inconstante. Essa situação pressagia uma precarização da condição existencial, da passagem do mal para o pior em que a, precarização do governo promove não só a desestabilização pelo desemprego, mas a condução da própria vida. Paira sobre nossa sociedade um horror de se perceber deficiente, inepto e ineficaz, fazendo com que os indivíduos percam sua autoestima, podendo levá-los a rejeição, proscrição e até mesmo exclusão. De modo perverso, aqueles que estão no poder tendem a perpetuar essa incerteza existencial, pois como bem expõe Bauman: 
“Afinal, o medo oficial de seus súditos é o que, em última instância, os mantém no poder” (p. $61)$.

O autor considera ainda que existia em curso um processo de erosão da soberania territorial uma vez que existia uma discrepância entre a globalização do poder e da política. Existia um fosso entre os súditos e aqueles que comandam, quase da mesma forma como no "medo cósmico", onde a comunicação entre os súditos e os representantes no poder está se perdendo, e com isso cessando a chance de diálogo entre esses.

Toda vez que uma sociedade fracassa ou começa a desintegrar faz surgir o discurso nacionalismo e étnico. Citando Eric Hobsbawm, o autor fundamenta seu argumento que as sociedades em declínio ou fracassadas investem suas esperanças em um salvador, geralmente nacionalista e belicoso que oferece como promessa o trancamento das portas ao mundo exterior. Muito embora vivamos em um mundo cada vez mais integrado, o que se vê é um desapontamento com o Estado-Nação em escala global, sem disposição a cooperação ou de construir benefícios globais comuns.

Bauman relata que embora o mundo seja cosmopolitizado, com fronteiras porosas e difusas, internacionalmente interdependentes, entretanto, falta consciência cosmopolita não só entre os indivíduos, mas também entre instituições para harmonizar a condição cosmopolita. $\mathrm{O}$ autor denuncia as promessas de alguns políticos contemporâneos, considerando-as impossíveis de serem concretizadas, devido à falta de poder efetivo para concretizá-las. $\mathrm{O}$ poder dos candidatos a tiranos reside na sua capacidade de promessa, que, ao que tudo indica, permanecerão nessa situação.

No capítulo 4, intitulado "Juntos e amontoados", o autor, nos lembra de nossa condição histórica de migrantes, que tiveram sua origem (geneticamente comprovada) no continente africano e de lá ganharam o Oriente Médio e os demais continentes. Ele assinala alguns momentos da história da humanidade, num primeiro onde o mundo conhecido era feito por pessoas que se conheciam devido ao seu grupamento reduzido. Um segundo momento seria aquele em que pessoas de um mesmo país, que possuem uma língua e legislação própria jamais chegariam a se conhecer em função das limitações dos meios tecnológicos que dispunham naquele momento histórico até chegar aos dias de hoje onde é factível estabelecer contato, de alguma forma, com os demais habitantes do planeta. Utilizando as ideias de Kwame Appiah, o autor considera que o grande desafio hoje seria fazer com que pessoas com opiniões divergentes vivam de acordo com a tribo global que nos tornamos, podendo nos 
levar ao bem-estar cooperativo ou a nossa extinção. Sobre a problemática do adensamento populacional, já teria sido refletida pelo filosofo Kant, segundo o qual diz que:

não é uma questão de filantropia, mas de direito. Hospitalidade significa o direito que tem um estrangeiro de não ser tratado de forma hostil pelo fato de estar em território alheio. O outro pode desprezar o estrangeiro, se isso pode realizar-se sem a ruína deste, mas, enquanto o estrangeiro se comportar amistosamente em seu posto, o outro não pode combatê-lo com hospitalidade. (p. 73)

O que Kant estaria defendendo não seria o fim dos Estados, mas sim, o direito de associarem-se e estabelecerem laços de amizade e enriquecimento mútuo. Todavia, no terreno da política a astúcia e honestidade são vistas como pares dialéticos.

A problemática em questão dos tempos modernos não é a simples troca de velhos por novos valores, mas sim a própria negação da moral em si como postulou Hannah Arendt. Isso fica evidente segundo Bauman, quando se analisam as guerras atuais, algumas onde se notam a defesa de princípios sacrossantos e de origem divina e de outro o discurso armado pela lógica e instrumentalizada pela razão, muito embora ambas dissimulem seus reais intensões e seu desejo de expansão.

Em oposição a esse espaço em permanente expansão estaria o domínio das obrigações morais. Existiria esse espaço indiferente à avaliação moral onde prevaleceriam a eficiência dos resultados. Mas a moral, ao contrário do que se pensa, não está fora de moda, é uma "propriedade muito cobiçada", e invejada por aqueles em função da autoridade que lhe confere seu possuidor e das vantagens inerentes a sua posse, com o intuito de legitimar a ideia de superioridade de uns sobre os outros.

Segundo Bauman, ter moral é saber traçar a diferença entre o bem e o mal, ser capaz de distinguir um do outro e consumá-los. Significaria reconhecer a própria responsabilidade de promover o bem e resistir ao mal. Existiria uma responsabilidade absoluta e daquela que deveria ser adequada às reais capacidades da condição humana comum, para se evitar assim escorregar para o Estado de Cegueira Moral$^{2}$. Bauman denuncia a renúncia de nossa responsabilidade moral. Reitera nosso desprezo por indivíduos que possuiriam características supostamente degradantes, que justificariam nossa falta de atenção e respeito em relação a

\footnotetext{
${ }^{2}$ Cegueira Moral é o título de uma das obras de Bauman composto por diálogos com Leonidas Donskis (filósofo, cientista político, historiador, professor de ciência política na Universidade de Vytautas Magnus e membro do Parlamento Europeu), demonstra que o mal é muito mais extenso em nossa realidade, indo das guerras até as circunstâncias cotidianas mais banais. A banalização em relação ao sofrimento do outro e da incapacidade ou recusa de compreendê-lo perpassa o cotidiano de nossa miopia ética, ou cegueira moral, como o próprio título da obra sugere. Estar no mundo segundo os autores é estar nas redes sociais. É nelas também que surge não só o discurso de liberdade de expressão e aproximação das pessoas é também contraditoriamente o espaço onde surgem novas formas de censura e demonstrações de ódio e intolerância.
} 
estes. A falta de interesse e até mesmo invisibilização desses indivíduos seria uma punição em relação aos vícios ou potenciais danosos que supostamente possuem. Cita o exemplo dos refugiados, que são acusados de possuir doenças terminais, de tentar islamizar a Europa ou de estar a serviço do Estado Islâmico. São muitas as calúnias e difamações em relação aos refugiados com o objetivo de desumanizá-los e por consequência desconsiderar seu caráter humano, portador de direitos. E assim, um tema que deveria permear as esferas éticas se torna um tema rotulado como uma questão de segurança, um crime, uma ameaça a ordem sendo reprimidos por forças policiais ou militares.

No $5^{\circ}$ capítulo, intitulado "Problemáticos, irritantes, indesejados: inadmissíveis", o autor traz a posição do primeiro ministro da Hungria, Viktor Orban, que este além de ser intolerante com o seu próprio povo e também com os migrantes. Todavia, mesmo muitas pessoas não concordassem com sua primeira intolerância, concordavam com a segunda.

Bauman, citando Michel Agier, argumenta que existiriam dois grandes grupos globais, um lado limpo, saudável e visível em contraposição a um outro mundo composto por remanescentes, residuais, sombrios, doentes e invisíveis. Esses indesejáveis, segundo o autor, geralmente são contidos em campos, circundado por muros, arame farpado, cercas elétricas ou mesmo confinado pelo vazio que os cerca.

O grande fluxo de "remanescentes", ou de pessoas indesejáveis, segundo o autor, foram além dos filtros estabelecidos pelas sociedades desenvolvidas, onde câmeras e detectores de todas as ordens são aplicados para visitantes esporádicos não são mais suficientes para o fluxo em massa dos tempos atuais.

Bauman critica também a postura dos países europeus em manter uma política de estancar o fluxo de migrantes, mas não a causa da migração provocada pela miséria e guerras.

No capítulo $6^{\circ}$, intitulado "Antropológicas versus temporárias: as raízes do ódio", Bauman inicia sua discussão com uma citação de Kant, que acreditava que todo ser humano traz dentro de si a ideia do que é certo ou errado, graças a sua racionalidade. Bauman destaca que a distinção entre o pensamento e ação, deve ser considerada quando refere ao momento em que pensamos e agimos quando estamos só, ou quando estamos junto com outros. De modo semelhante, Leon Festinger refletiu sobre as rotas de fuga da dissonância cognitiva que surge um hiato entre o conhecimento e a conduta moral. Esses caminhos têm em comum é o fato de tentarem se afastar do autodesprezo, tentando afastar de si a hipocrisia e a mentira de forma que esse exame chega a consciência do mentiroso. Para que tal análise não seja feita 
pelo indivíduo esse se firma numa "(auto)confiança" e numa fé e firme convicção espiritual, evitando muitas vezes que não se paute em provas e sim em meras convicções.

Quando muitos são confrontados sobre a falta de bases materiais para suas ações e pensamentos, esses recorrem a prática realizada por um grande número de indivíduos ou a maioria. "Quanto mais as pessoas o fazem, mais segura e autoconfiante é a imperturbabilidade de minha fé". (p. 100).

Novas circunstâncias estariam surgindo e afetando nossos pensamentos e ações. Nós como as outras pessoas estaríamos vivendo em dois mundos, um on-line e outro off-line. A passagem de um mundo ao outro é tão tênue, quase difícil de distinguir, já que no mundo online, não existem controles de migração ou controle de fronteiras como as que existem no mundo off-line.

Com frequência estamos em dois mundos ao mesmo tempo, enviando mensagens instantâneas para toda parte do mundo enquanto estamos em convivência com amigos e familiares. Enquanto no mundo off-line o indivíduo não está no controle, as relações entre os indivíduos são mais diretas e reguladas e vigiada por outros indivíduos e instituições.

Muitas situações estão fora de nosso controle no mundo off-line e podem resultar na inclusão ou exclusão dos indivíduos.

Já no mundo online o indivíduo não só é responsável, ele está no controle, administrando as circunstâncias e sendo juiz daqueles que supostamente estão sob seu julgo. "Eu pertenço ao mundo off-line, enquanto o mundo online pertence a mim". (p. 102). Enquanto o mundo off-line possui situações que não podem ser controladas, o mundo on-line está completamente no controle de seus administradores para que possam concretizar seus desejos. O mundo off-line vem com a promessa de nos libertar de desconfortos, inconveniências e nos libertar das preocupações, muito embora não os resolva, é uma forma do que o autor chama de "jogar a sujeira para baixo do tapete".

Diante das demandas de um mundo pós-moderno, do qual demanda dos indivíduos que resolvam problemas, sem que tenham as habilidades ou ferramentas necessárias para isso. Tais frustrações são nominadas por alguns como destino, muito embora, tal palavra evidencie o fracasso ainda maior. Na falta de causa para os problemas e com o intuito de preservar o auto-respeito e a dignidade, muitos indivíduos buscam culpados para seus problemas e os imigrantes acabam sendo os escolhidos como o bode expiatório de todos os problemas.

Em um mundo cada vez mais densamente ocupado, conectado e mais fluido, o autor reitera a necessidade de diálogo como uma das poucas saídas para os problemas enfrentados. 
As conversas nas fronteiras podem assim ser de trocas positivas ou conflitos, sendo que o diálogo é inevitável.

\section{REFERÊNCIAS}

BAUMAN, Z. Estranhos à nossa porta. Tradução. Carlos Alberto Medeiros. Rio de Janeiro: Zahar, 2017.

BAUMAN, Z.; DONKIS, L. Cegueira Moral: a perda da sensibilidade na modernidade líquida. Tradução. Carlos Alberto Medeiros. Rio de Janeiro: Zahar, 2014. 